\title{
A simple, economical and reproducible protein extraction protocol for proteomics studies of soybean roots
}

\author{
Elisete Pains Rodrigues ${ }^{1,2}$, Adalgisa Ribeiro Torres ${ }^{1}$, Jesiane Stefânia da Silva Batista ${ }^{1}$ Luciano Huergo $^{3}$ \\ and Mariangela Hungria ${ }^{1}$ \\ ${ }^{1}$ Embrapa Soja, Londrina, PR, Brazil. \\ ${ }^{2}$ Departamento de Biologia, Universidade Estadual de Londrina, Londrina, PR, Brazil. \\ ${ }^{3}$ Deptartamento de Bioquímica e Biologia Molecular, Universidade Federal do Paraná, Curitiba, PR, \\ Brazil.
}

\begin{abstract}
Sample preparation is a critical step in two-dimensional gel electrophoresis (2-DE) of plant tissues. Here we describe a phenol/SDS procedure that, although greatly simplified, produced well-resolved and reproducible 2-DE profiles of protein extracts from soybean [Glycine max (L.) Merril] roots. Extractions were made in three replicates using both the original and simplified procedure. To evaluate the quality of the extracted proteins, ten spots were randomly selected and identified by mass spectrometry (MS). The 2-DE gels were equally well resolved, with no streaks or smears, and no significant differences were observed in protein yield, reproducibility, resolution or number of spots. Mass spectra of the ten selected spots were compared with database entries and allowed high-quality identification of proteins. The simplified protocol described here presents considerable savings of time and reagents without compromising the quality of 2-DE protein profiles and compatibility with MS analysis, and may facilitate the progress of proteomics studies of legume-rhizobia interactions.
\end{abstract}

Key words: 2-DE, protein extraction, proteomics, soybean roots, symbiosis.

\section{Introduction}

Sample preparation, a critical step in proteomics research using two-dimensional gel electrophoresis (2-DE) (Saravanan and Rose, 2004) is particularly troublesome in studies with plants, the tissues of which are often rich in proteases and interfering compounds such as polysaccharides, lipids and phenols (Carpentier et al., 2005). Such contaminants interfere with protein separation and analysis, resulting in horizontal and vertical streaking, smearing, and in decreased number of distinctly resolved spots. In addition, plant tissues have low protein content in comparison to animal and bacterial sources, therefore effective extraction of proteins is essential to obtain successful results (Saravanan and Rose, 2004; Carpentier et al., 2005).

Proteomics studies allow quantitative and qualitative comparisons of proteins, therefore any loss of protein at any step in the analysis process is critical. Furthermore, it is essential to obtain high-quality gels with well-resolved spots showing reproducible protein patterns (Hurkman and Tanaka, 1986). The extraction method must preserve the quality

Send correspondence to Mariangela Hungria. Embrapa Soja, Caixa Postal 231, 86001-970 Londrina, PR, Brazil. E-mail: hungria@cnpso.embrapa.br; hungria@pq.cnpq.br. and quantity of the proteins extracted and for that sample treatment must be kept to a minimum number of steps, to minimize protein loss (Hurkman and Tanaka, 1986; Westermeier and Naven, 2002).

Root-nodule symbioses of rhizobia with legumes, resulting in biological nitrogen fixation, represent a major subject of study, due to their contribution to the global nitrogen cycle and to the economic importance of legume crops such as soybean [Glycine max (L.) Merr.]. Research in our laboratory is focused mainly on soybean and common bean (Phaseolus vulgaris L.) symbioses, generally involving nodulated roots. Although a one-step procedure for protein extraction would be highly desirable, no single method of sample preparation can be universally applied to 2-DE analysis (Dunn, 1999). Due to the need for a simple method that could be applied routinely to proteomics studies of symbiotic interactions, we optimized a phenol/SDS based method described previously (Wang et al., 2006). The simplified method presented here was able to produce well-resolved and reproducible 2-DE protein profiles of soybean roots and it was also compatible with matrixassisted laser desorption ionization time-of-flight/mass spectrometry (MALDI-TOF/MS) analysis, enabling the successful identification of the proteins. This study offers a 
useful workflow for proteomics of legume-rhizobia symbioses using 2-DE and MS analysis.

\section{Materials and Methods}

\section{Plant material}

Surface-sterilized soybean seeds were inoculated with Bradyrhizobium japonicum strain CPAC 15 (= SEMIA 5079) and grown aseptically receiving sterile $\mathrm{N}$-free nutrient solution. Roots of 13-day-old soybean seedlings were harvested, immediately frozen in liquid nitrogen and stored at $-80^{\circ} \mathrm{C}$ until extraction. At this stage only nodule primordia were present, with no fully developed nodules. Roots were finely powdered by grinding in a mortar and pestle with liquid nitrogen, which, as emphasized earlier (Giavalisco et al., 2003), is a critical step in obtaining high resolution of proteins in 2-DE gels.

\section{Protein extraction}

The simplified protocol is based on the phenol/SDS method described previously (Wang et al., 2006), which comprises three successive washes with trichloroacetic acid (TCA) in acetone, methanol and acetone, followed by a vacuum-drying step before the phenol/SDS extraction. The modifications in our method are the elimination of three preliminary wash steps and of the vacuum-drying step, representing considerable economy of reagents and time (Figure 1).

For comparison, proteins were extracted from soybean root samples using the simplified method described here and the original phenol/SDS method (Wang et al., 2006). For both methods, protein extraction and 2-DE were performed with three replicates and comparisons were made for protein yields and 2-DE gel resolution and reproducibility.

Pulverized samples $(250 \mathrm{mg})$ were resuspended in $0.8 \mathrm{~mL}$ of Tris-buffered phenol, $\mathrm{pH} 8.0$, and $0.8 \mathrm{~mL}$ of SDS buffer [0.1 M Tris-HCl pH 8.0, 2\% SDS, 5\% $\beta$-mercaptoethanol, $30 \%$ sucrose, $1 \mathrm{mM}$ phenylmethylsulfonyl fluoride (PMSF)]. The samples were vigorously vortexed for $10 \mathrm{~min}$ and centrifuged at $16,000 \mathrm{~g}$ for $5 \mathrm{~min}$ at $4{ }^{\circ} \mathrm{C}$, and the top phenol layer $(0.5 \mathrm{~mL})$ was transferred to a new tube. Proteins were precipitated for $2 \mathrm{~h}$ at $-20{ }^{\circ} \mathrm{C}$ with three volumes of pre-cooled $0.1 \mathrm{M}$ ammonium acetate in absolute methanol and then pelleted by centrifugation $(16,000 \mathrm{~g}$ for 5 min at $4{ }^{\circ} \mathrm{C}$ ). The pellet was washed once with pre-cooled $0.1 \mathrm{M}$ ammonium acetate in methanol and once with precooled $80 \% \mathrm{v} / \mathrm{v}$ acetone, followed by vacuum drying.

The protein pellets were solubilized in isoelectric focusing (IEF) buffer (7 M urea, $2 \mathrm{M}$ thiourea, 4\% 3-[(3cholamidopropyl)dimethylammonio]-1-propanesulfonate (CHAPS), $20 \mathrm{mM}$ dithiothreitol (DTT), 0.5\% immobilized $\mathrm{pH}$ gradient (IPG) buffer, $\mathrm{pH}$ 3-10 or 4-7), by pipetting followed by sonication for $30 \mathrm{~s}(2 \mathrm{x})$ in a water bath sonicator at $15-20^{\circ} \mathrm{C}$. The solubilized proteins were quantified using

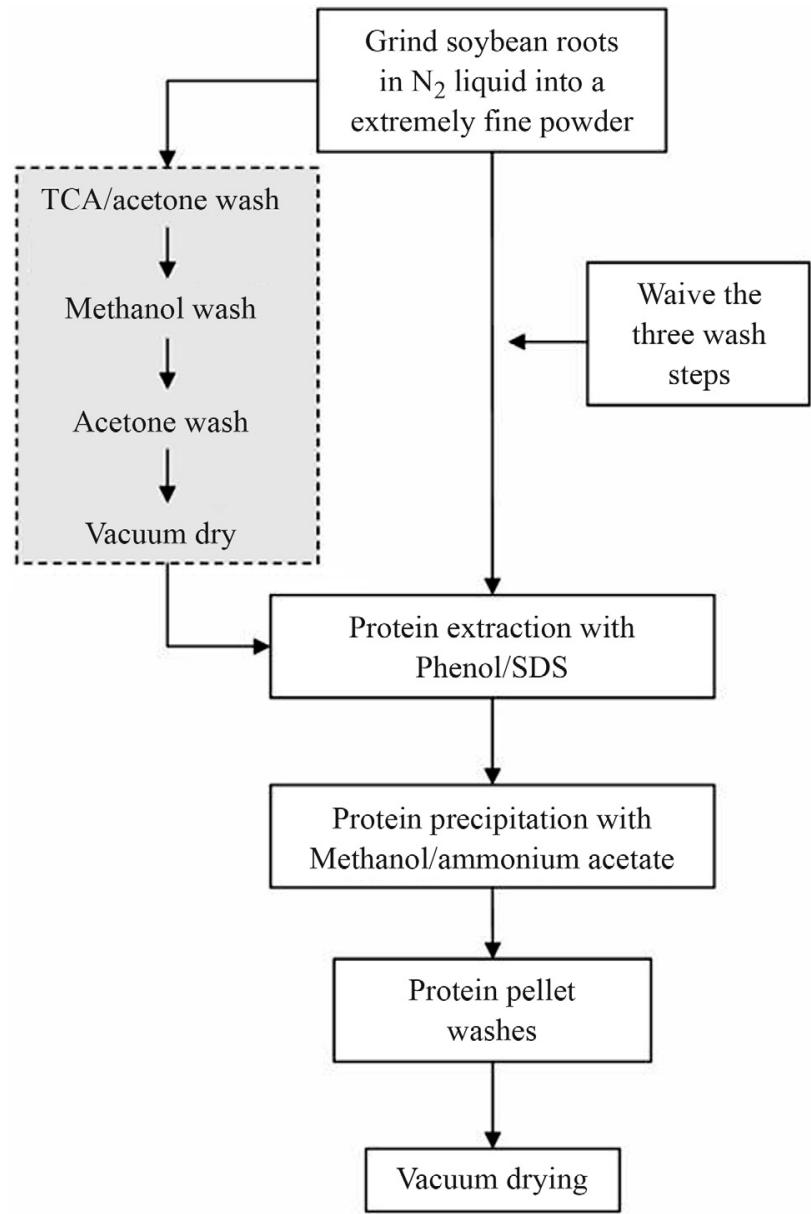

Figure 1 - Schematic outline of the protocol presented here. The modifications performed on the original phenol/SDS method (Wang et al., 2006) are shown in the dashed frames with a gray background.

the Bradford protein assay (Bradford, 1976) with a bovine serum albumin (BSA) standard curve.

\section{Isoelectric focusing}

For the first dimension, $350 \mu \mathrm{g}$ of solubilized protein was transferred to a fresh tube and the volume was brought up to $0.25 \mathrm{~mL}$ with De Streak buffer (GE Biosciences). The protein suspensions were rehydrated overnight into IPG strips (linear pH 3-10 or 4-7, $13 \mathrm{~cm}$, GE Biosciences). Next, IEF was carried out on the IPGphor II (Amersham Biosciences) with a current limit of $50 \mu \mathrm{A} /$ strip at $20^{\circ} \mathrm{C}$ using a focusing protocol: $1 \mathrm{~h}$ at $200 \mathrm{~V}, 1 \mathrm{~h}$ at $500 \mathrm{~V}, 1 \mathrm{~h}$ at $1,000 \mathrm{~V}$ (gradient), $2.5 \mathrm{~h}$ at $8,000 \mathrm{~V}$ (gradient) and then $1.5 \mathrm{~h}$ at $8,000 \mathrm{~V}$, reaching a total of $24.8 \mathrm{kVh}$.

\section{SDS-PAGE}

Prior to second dimension analysis, the IPG strips were gently agitated for $30 \mathrm{~min}$ in equilibration buffer emended with $1 \%(\mathrm{w} / \mathrm{v})$ of DTT followed by agitation for $30 \mathrm{~min}$ in buffer emended with $3.5 \%(\mathrm{w} / \mathrm{v})$ iodoacetamide. Then, the IPG strips were loaded onto acrylamide gels 
$(11.6 \%)$ and overlaid with agarose solution. Second dimension electrophoresis was carried out using an SE 600 Ruby (GE Biosciences) with the first current cycle at $15 \mathrm{~mA}$ per gel $(30 \mathrm{~min})$ and a second cycle at $30 \mathrm{~mA}$ per gel $(4 \mathrm{~h})$. Next, gels were stained overnight with Comassie Brilliant Blue (CBB) R-350 (GE Biosciences), destained in a solution of $40 \%$ ethanol and $10 \%$ acetic acid and scanned (ImageScanner LabScan v. 5.0). The 2-DE gel images were analyzed using the Image Master 2-D Platinum v.5.0 software (GE Biosciences).

\section{MALDI-TOF/MS analysis and protein identification}

Randomly selected spots were excised and processed as described before (Chaves et al., 2009), with slight modifications on the digestion procedure, done with trypsin (Gold, mass spectrometry grade, Promega, Madison, WI) at $37^{\circ} \mathrm{C}$ overnight. For MALDI-TOF analysis, $0.5 \mu \mathrm{L}$ of the tryptic peptide was mixed with a matrix solution of saturated $\alpha$-cyano-4-hydroxycinnamic acid (HCCA) in acetonitrile 50\%/trifluoroacetic acid (TFA) $0.1 \%$. The mixture was spotted onto a MALDI sample plate and allowed to crystallize at room temperature. The same procedure was used for the standard peptide calibration mix (Bruker Daltonics).

Mass spectra were acquired using a MALDI-TOFMS Autoflex spectrometer (Bruker Daltonics) operated in the reflector for MALDI-TOF peptide mass fingerprint (PMF) with a fully manual mode, using FlexControl software. For protein identification, PMFs generated were searched against the NCBInr database using the MASCOT software (Matrix Science). For the protein search, monoisotopic masses were used and a peptide tolerance of $100 \mathrm{ppm}$ and one missed cleavage was allowed. Carbamidomethylation of cysteine and oxidation of methionine were taken into consideration as fixed and variable modifications, respectively.

\section{Results and Discussion}

Quantitative comparison of protein samples obtained with the two extraction protocols indicated that protein yields were statistically equal (ANOVA, $\mathrm{p}<0.05$ ) (Table 1). The protein values recovered by both methods were within the range of those reported in the literature for plant roots (Westermeier and Naven, 2002; Saravanan and Rose, 2004); however, the slightly higher protein yield obtained in our modified method might be attributed to the removal of the preliminary washes, which were part of the original method, and potentially preventing protein loss. Any increase in protein yield is important when the material under analysis is limited or when the protein content is low, as is the case with soybean roots.

A prerequisite, but also a major challenge in proteomic analysis, is the separation of proteins from complex biological samples with high resolution and reproducibly (Görg et al., 2004). Both the original and the modified methods tested in this study have proven to be suitable to obtain proteins from soybean roots, resulting in high-quality 2-DE gels (Figure 2). The proteins were well resolved on gels, with no streaks or smears, indicating insignificant degradation of proteins and efficient removal of contaminant compounds.

The removal of interfering compounds prior to protein extraction may also be critical (Saravanan and Rose, 2004; Carpentier et al., 2005), and washes with TCA and acetone are usually performed to eliminate salts, polyphenols, and also to minimize protein degradation (Görg et al., 2004). However, no evident improvements were observed by preliminary TCA/acetone, methanol and acetone washes (Figure 2), proving that our modified protocol is suitable both for removing interfering compounds and minimizing protein degradation in extracts from soybean root tissues.

Another limitation may result from changes in factors such as $\mathrm{pH}$, ionic strength, and temperature that may lead to selective losses of proteins; the more steps in the extraction process, the greater are the chances of losing or erroneously detecting differentially expressed protein subsets (Rose $e t$ al., 2004). Decreasing the number of treatment steps in our method may help to avoid protein losses and, at the same time, enable high-quality images, with no need of cleanup steps to reduce background smear or to remove horizontal and/or vertical streaks.

Both protocols gave well-resolved and reproducible spot patterns (Figure 2). Fully automatic spot detection and matching were performed, and the data indicating the reproducibility of each protocol are shown in Table 1 . Statistically similar numbers (ANOVA, $\mathrm{p}<0.05$ ) of detected spots were observed when both methods were compared. Spots matched in all three replicate gels ranged from $84 \%$ in the original phenol/SDS (Wang et al., 2006) to $88 \%$ in our modified method (Table 1).

Table 1 - Recovered protein yield and reproducibility from soybean root proteins using two protein extraction methods and IPG strips (13 cm) with a linear $\mathrm{pH}$ range 3-10. a: Values represent the means of three independent biological replicates with standard deviation in parentheses; NS: Values show no statistically significant difference (ANOVA test, $\mathrm{p}<0.05$ ).

\begin{tabular}{llcccc}
\hline Extraction method & $\begin{array}{c}\text { Protein yield } \\
(\mathrm{mg} / \mathrm{g} \text { roots })^{\mathrm{a}}\end{array}$ & $\begin{array}{c}\text { Number of } \\
\text { detected spots }^{\mathrm{a}}\end{array}$ & $\begin{array}{c}\text { Matched spots } \\
(\%)^{\mathrm{a}}\end{array}$ & $\begin{array}{c}\text { Spots with CV value } \\
<30 \%(\%)\end{array}$ & $\begin{array}{c}\text { Correlation value }\left(\mathrm{R}^{2}\right) \\
\text { of matched spots }\end{array}$ \\
\hline Original phenol/SDS & $1.61( \pm 0.11)^{\mathrm{NS}}$ & $646( \pm 33)^{\mathrm{NS}}$ & 84 & 91 & 0.963 \\
Modified phenol/SDS & $1.82( \pm 0.09)^{\mathrm{NS}}$ & $715( \pm 40)^{\mathrm{NS}}$ & 88 & 88 & 0.924 \\
\hline
\end{tabular}



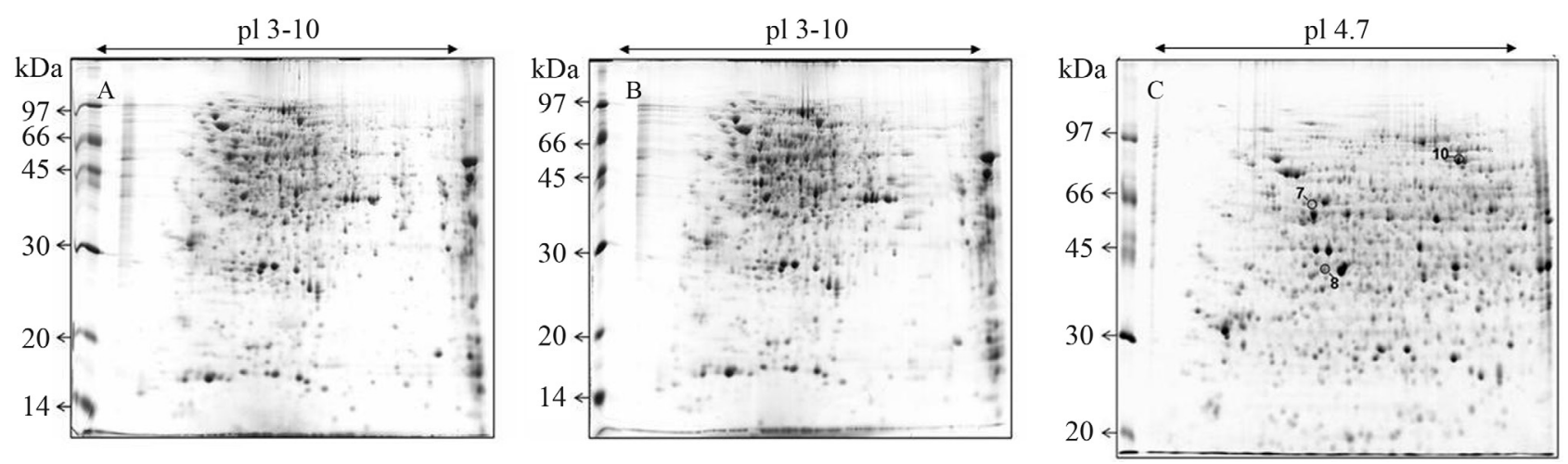

Figure 2 - 2-DE analysis from soybean root proteins extracted using the modified phenol/SDS extraction method (A, C) and original phenol/SDS method (B) (Wang et al., 2006). Solubilized proteins $(350 \mu \mathrm{g})$ were focalized using IPG strips $(13 \mathrm{~cm})$ with a linear $\mathrm{pH}$ range 3-10 (A, B) or a linear $\mathrm{pH}$ range 4-7 (C). SDS-PAGE was performed in a vertical 11.6\% acrylamide gel and stained with CBB R 350. The molecular weight of protein standards is indicated on the left.

To assess reproducibility of the protein patterns, we performed a correlation analysis and estimated the coefficient of variation $(\mathrm{CV})$ of the calculated normalized spot volumes $(\% \mathrm{vol})$ from pairwise matched spots obtained in each extraction protocol (Table 1). Considering the similarities between gels, the correlation $\left(\mathrm{R}^{2}\right)$ of the $\%$ vol of spots was higher than 0.92 for both protocols, indicating high reproducibility. In agreement with previously reported data (Molloy et al., 2003), CV values lower than 30\% were considered as indicative of the quality of the experiment, and for our modified method and the original phenol/SDS method (Wang et al., 2006), the CV\% for the \%vol was lower than $30 \%$ for $88 \%$ and $91 \%$ of matched spots, respectively. CV values higher than $30 \%$ were obtained only for spots prone to mismatches due to local pattern distortions.

In 2-DE gels using 3-10 pH IPG strips, about $65 \%$ of total spots were concentrated in the 4-7 $\mathrm{pH}$ range, prompting us to choose this narrower range to increase the resolution of the proteins concentrated in this $\mathrm{pH}$ region and to facilitate comparative studies of soybean root proteins. A total of $512 \pm 42$ spots were detected on the gel by using a pH 4-7 IPG strip (Figure 2). Three of these spots were randomly selected (Figure 2) and subjected to MALDI-TOF mass spectrometry analysis. The searching of MS data against the NCBInr protein database using Mascot allowed the protein identification of all selected spots, as listed (Table 2). In all cases, both significant protein score values in Mascot identifications and a high percentage of sequence coverage were obtained. The high quality of MS data indicated the compatibility of the optimized protein extraction method with MALDI-TOF/MS.

Among the proteins identified, one is related to the peroxisomal betaine-aldehyde dehydrogenase that catalyzes the conversion of betaine aldehyde to betaine, a carbon or nitrogen source and an important osmoprotectant agent (Pocard et al., 1997). Betaine was also known to be one of the non-flavonoid compounds that is able to induce nod genes in rhizobia (Subramanian et al., 2007).

We have also identified a cytosolic glutamine synthetase $\beta 1$ (GS- $\beta 1$ ), a key enzyme responsible for the primary assimilation of ammonia in root nodules of legumes. The $\beta 1$-form is considered the constitutive isoform, but it is expressed in relatively high levels in nodules. It has been demonstrated that, in soybean, the GS- $\beta 1$ gene $(\operatorname{gln} \beta 1)$ is induced in nodules by reduced $\mathrm{N}$ or its assimilation products, showing that its expression is regulated by physiological changes (Morey et al., 2002). Methionine synthase was the third identified protein.

In conclusion, the protocol presented here, although greatly simplified, allowed well-resolved and reproducible spot patterns on 2-DE gels of soybean root proteins. Our sample preparation helped avoid protein modifications or losses and facilitated reproducibility. The modified method presented in this study proved to be efficient, simple, economical and appropriate for proteomics studies with

Table 2 - Selected protein spots identified by MALDI-TOF.

\begin{tabular}{|c|c|c|c|c|c|c|c|c|c|}
\hline \multirow[t]{2}{*}{ Spot no. } & \multirow[t]{2}{*}{ Protein name and organism } & \multirow{2}{*}{$\begin{array}{c}\text { GenBank accession } \\
\text { number }\end{array}$} & \multirow{2}{*}{$\begin{array}{l}\text { Mascot } \\
\text { score }\end{array}$} & \multirow[t]{2}{*}{$\mathrm{N}^{1}$} & \multirow[t]{2}{*}{$\operatorname{Cov}^{2}$} & \multicolumn{2}{|c|}{$\mathrm{pI}^{3}$} & \multicolumn{2}{|c|}{$\mathrm{MW}^{4}(\mathrm{kDa})$} \\
\hline & & & & & & Exp. $^{5}$ & The. ${ }^{6}$ & Exp. $^{5}$ & The. ${ }^{6}$ \\
\hline 7 & Peroxisomal betaine-aldehyde dehydrogenase (Glycine max) & gi|167962545 & 79 & 10 & 22 & 5.03 & 5.23 & 65 & 55.4 \\
\hline 8 & Cytosolic glutamine synthetase (Glycine max) & gi|10946357 & 78 & 9 & 29 & 5.15 & 5.48 & 45 & 39.1 \\
\hline 10 & Methionine synthase (Glycine max) & gi|33325957 & 107 & 13 & 18 & 6.26 & 5.93 & 85 & 84.4 \\
\hline
\end{tabular}

${ }^{1}$ Number of peptides identified; ${ }^{2}$ Sequence coverage (\%); ${ }^{3}$ Isoelectric point; ${ }^{4}$ Molecular weight (kDa); ${ }^{5}$ Experimental value; ${ }^{6} \mathrm{Theoretical} \mathrm{value.}$ 
soybean roots, and will likely be applicable to the root tissues of other plants.

\section{Acknowledgments}

Research described herein was partially supported by CNPq (Conselho Nacional de Desenvolvimento Científico e Tecnológico, Brazil), Project Genosoja. The MALDITOF system was acquired with resources from Fundação Araucária. The authors would like to thank Dr. E.M. Souza and F. Pedrosa for their help and suggestions in the proteome analysis. E. Rodrigues and A. Torres received fellowships from $\mathrm{CNPq}$ and J.S.S. Batista a fellowship from CAPES (Coordenação de Aperfeiçoamento de Pessoal de Nível Superior, Brazil). M. Hungria is also a research fellow of CNPq.

\section{References}

Bradford MM (1976) A dye binding assay for protein. Anal Biochem 72:248-254.

Carpentier SC, Witters E, Laukens K, Deckers RS and Panis B (2005) Preparation of protein extracts from recalcitrant plant tissues: An evaluation of different methods for two-dimensional gel electrophoresis analysis. Proteomics 5:24972507.

Chaves DFS, Souza EM, Monteiro RA and Pedrosa FO (2009) A two-dimensional electrophoretic profile of the proteins secreted by Herbaspirillum seropedicae strain Z78. J Proteomics 73:50-56.

Dunn MJ (1999) Detection of total proteins on western blots of 2-D polyacrylamide gels. In: Link AJ (ed) Methods in Molecular Biology: 2-D Proteome Analysis Protocols, vol. 112. Humana Press, New Jersey, pp 319-329.

Giavalisco P, Nordhoff E, Lehrach H, Gobom J and Klose J (2003) Extraction of proteins from plant tissues for twodimensional electrophoresis analysis. Electrophoresis 24:207-216.
Görg A, Weiss W and Dunn MJ (2004) Current two-dimensional electrophoresis technology for proteomics. Proteomics 4:3665-3685.

Hurkman WJ and Tanaka CK (1986) Solubilization of plant membrane proteins for analysis by two-dimensional gel electrophoresis. Plant Physiol 81:802-806.

Molloy MP, Brzezinski EE, Hang J, McDowell MT and VanBogelen RA (2003) Overcoming technical variation and biological variation in quantitative proteomics. Proteomics 3:1912-1919.

Morey KJ, Ortega JL and Sengupta-Gopalan C (2002) Cytosolic glutamine synthetase in soybean is encoded by a multigene family, and the members are regulated in an organ-specific and developmental manner. Plant Physiol 128:182-193.

Pocard JA, Vincent N, Boncompagni E, Smith LT, Poggi MC and Le Rudulier D (1997) Molecular characterization of the bet genes encoding glycine betaine synthesis in Sinorhizobium meliloti 102F34. Microbiology 143:1369-1379.

Rose JKC, Bashir S, Giovannoni JJ, Jahn MM and Saravanan RS (2004) Tackling the plant proteome: Practical approaches, hurdles and experimental tools. Plant J 39:715-733.

Saravanan RS and Rose JKC (2004) A critical evaluation of sample extraction techniques for enhanced proteomic analysis of recalcitrant plant tissues. Proteomics 4:2522-2532.

Subramanian S, Stacey G and Yu O (2007) Distinct, crucial roles of flavonoids during legume nodulation. Trends Plant Sci 12:282-285.

Wang W, Vignani R, Scali M and Cresti M (2006) A universal and rapid protocol for protein extraction from recalcitrant plant tissues for proteomic analysis. Electrophoresis 27:27822786.

Westermeier R and Naven T (2002) Proteomics in Practice: A Laboratory Manual of Proteome Analysis. Wiley-VCH Verlag-GmbH, Weinheim, 342 pp.

License information: This is an open-access article distributed under the terms of the Creative Commons Attribution License, which permits unrestricted use, distribution, and reproduction in any medium, provided the original work is properly cited. 